\title{
NULIDAD DE OFICIO DE LOS ACTOS ADMINISTRATIVOS
}

\author{
Carlos Rodríguez MANRIQue* \\ Universidad de Lima, Lima, Perú \\ Recibido: 17/12/2020 Aceptado: 11/1/2020 \\ doi https://doi.org/10.26439/iusetpraxis2021.n053.5055
}

\begin{abstract}
RESUMEN. La atribución que tienen los entes de la Administración Pública de anular de oficio sus propios actos administrativos, sin necesidad de recurrir a una autoridad jurisdiccional, constituye una potestad pública que genera una permanente tensión entre el principio de legalidad y la seguridad jurídica. Este artículo aborda esta manifestación de la revisión de oficio de las actuaciones administrativas partiendo de la distinción de figuras como validez, nulidad, revocación e inexistencia, para luego desarrollar, de manera crítica, la forma como la normativa administrativa vigente contempla la correlación de fuerzas entre los principios antes mencionados. Asimismo, se exponen las garantías procesales y los presupuestos especiales que deben presentarse para que las entidades públicas puedan ejercer correctamente esta potestad, sin afectar los derechos de los administrados.
\end{abstract}

PALABRAS CLAVE: acto administrativo / nulidad de acto administrativo / revisión de oficio de actos administrativos / autotutela / agravio al interés público / invalidez del acto administrativo / proceso de lesividad

\footnotetext{
* Abogado por la Pontificia Universidad Católica del Perú. Máster en Gestión Pública por la Universidad Autónoma de Barcelona, Universidad Pompeu Fabra y ESADE, España. Profesor de derecho administrativo en la Universidad de Lima. Socio de Amprimo, Flury, Barboza \& Rodríguez Abogados.
} 


\title{
NULLITY OF ADMINISTRATIVE ACTIONS ON THE ADMINISTRATION'S OWN ACCORD
}

\begin{abstract}
The faculty that Public Administration entities have to nullify their administrative actions on their own accord, without the need of appealing to a jurisdictional authority, generates a permanent tension between the principles of legality and legal security. The author tackles this public administration faculty starting from the distinction between figures like validity, nullity, revocation and inexistence, to then critically develop the way in which current administrative norms contemplate the correlation of forces between the already mentioned principles. Furthermore, this article develops the basic procedural guarantees and special requirements that must be present so that public entities may apply this faculty correctly, without affecting the administered individuals.
\end{abstract}

KEYWORDS: administrative action / nullity of administrative action / review of administrative actions on the administration's own accord / self-tutelage / affront against public interest / invalidity of administrative acts / harmfulness process 


\section{INTRODUCCIÓN}

A diferencia de los actos jurídicos generados en el ámbito del derecho privado, cuya nulidad debe ser declarada por una autoridad jurisdiccional, los actos administrativos pueden ser declarados como nulos directamente por la propia Administración, en la medida en que estos hayan sido producidos con vicios que afecten su validez y siempre que agravien el interés público o lesionen derechos fundamentales.

En el derecho civil, la regla es que los particulares (o el Ministerio Público en las materias de su competencia) sean los que peticionan a la autoridad jurisdiccional que declare la nulidad absoluta de los actos jurídicos. Solo por excepción, en los casos en que la nulidad sea manifiesta, la autoridad jurisdiccional podrá declararla de oficio'. Claro está que la actuación nulificante de oficio del juez o del árbitro estará supeditada siempre a la existencia de un proceso judicial o arbitral, respectivamente, planteado e iniciado por un accionante. Ninguna autoridad jurisdiccional puede impulsar de oficio el inicio de un proceso destinado a que se anule un acto jurídico, a diferencia de lo que ocurre con la Administración, que sí cuenta con la potestad de iniciar de oficio un procedimiento administrativo tendiente a declarar la nulidad de sus propios actos.

La nulidad de los actos administrativos puede ser invocada también por los administrados (al igual que ocurre en el derecho civil con la nulidad de los actos jurídicos, que puede ser invocada por los particulares). En este caso, la nulidad debe ser formulada a través de los recursos administrativos pertinentes, como lo establece el numeral 11.1 del artículo 11 del texto único ordenado de la Ley 27444, Ley del Procedimiento Administrativo General, aprobado por el Decreto Supremo 004-2019-JUS (en lo sucesivo, LPAG) ${ }^{2}$. Estos recursos son la reconsideración, la apelación y, excepcionalmente, la revisión.

La potestad de la Administración de declarar la nulidad de sus propios actos administrativos, sin necesidad de recurrir a la autoridad jurisdiccional, se encuentra prevista

1 De acuerdo con el artículo 220 del Código Civil: “La nulidad a que se refiere el artículo 219 puede ser alegada por quienes tengan interés o por el Ministerio Público. Puede ser declarada de oficio por el juez cuando resulte manifiesta. No puede subsanarse por la confirmación".

2 LPAG. Artículo 11.- Instancia competente para declarar la nulidad

11.1 Los administrados plantean la nulidad de los actos administrativos que les conciernan por medio de los recursos administrativos previstos en el título III, capítulo II, de la presente ley.

11.2 La nulidad de oficio será conocida y declarada por la autoridad superior de quien dictó el acto. Si se tratara de un acto dictado por una autoridad que no está sometida a subordinación jerárquica, la nulidad se declarará por resolución de la misma autoridad. La nulidad planteada por medio de un recurso de reconsideración o de apelación será conocida y declarada por la autoridad competente para resolverlo.

11.3 La resolución que declara la nulidad dispone, además, lo conveniente para hacer efectiva la responsabilidad del emisor del acto inválido, en los casos en que se advierta ilegalidad manifiesta, cuando sea conocida por el superior jerárquico. 
en el artículo 211 de la LPAG, y constituye una clara manifestación de la denominada autotutela administrativa ${ }^{3}$.

La reciente modificación de la LPAG, por el Decreto Legislativo 1272, ha introducido importantes modificaciones al tratamiento de la nulidad de oficio de los actos administrativos, lo cual nos ha motivado a escribir el presente artículo. Algunos cambios son buenos y eran necesarios, pero otros - como el caso específico de la ampliación del plazo prescriptorio para declarar de oficio la nulidad de los actos administrativos a dos años - son severamente negativos, porque agravan la disparidad que existe entre la Administración y los administrados, además de representar un debilitamiento de la seguridad jurídica.

\section{ACLARANDO LAS NOCIONES DE VALIDEZ, EFICACIA Y NULIDAD DE LOS ACTOS ADMINISTRATIVOS}

\section{No es infrecuente que los operadores del derecho confundan los alcances de las nociones} de validez, eficacia y nulidad de los actos administrativos. Este hecho puede resultar más

3 LPAG. Artículo 211.- Nulidad de oficio

211.1 En cualquiera de los casos enumerados en el artículo 10, puede declararse de oficio la nulidad de los actos administrativos, aun cuando hayan quedado firmes, siempre que agravien el interés público o lesionen derechos fundamentales.

211.2 La nulidad de oficio solo puede ser declarada por el funcionario jerárquico superior al que expidió el acto que se invalida. Si se tratara de un acto emitido por una autoridad que no está sometida a subordinación jerárquica, la nulidad es declarada por resolución del mismo funcionario.

Además de declarar la nulidad, la autoridad puede resolver sobre el fondo del asunto, de contarse con los elementos suficientes para ello. En este caso, este extremo solo puede ser objeto de reconsideración. Cuando no sea posible pronunciarse sobre el fondo del asunto, se dispone la reposición del procedimiento al momento en que el vicio se produjo.

En caso de declaración de nulidad de oficio de un acto administrativo favorable al administrado, la autoridad, previamente al pronunciamiento, le corre traslado, otorgándole un plazo no menor de cinco (5) días para ejercer su derecho de defensa.

211.3 La facultad para declarar la nulidad de oficio de los actos administrativos prescribe en el plazo de dos (2) años, contado a partir de la fecha en que hayan quedado consentidos.

Respecto de la nulidad de los actos previstos en el numeral 4 del artículo 10, el plazo para declarar la nulidad de oficio se extiende hasta un (1) año después de la notificación de la resolución correspondiente a la sentencia penal condenatoria firme.

211.4 En caso de que haya prescrito el plazo previsto en el numeral anterior, solo procede demandar la nulidad ante el Poder Judicial vía el proceso contencioso administrativo, siempre que la demanda se interponga dentro de los tres (3) años siguientes a contar desde la fecha en que prescribió la facultad para declarar la nulidad en sede administrativa.

211.5 Los actos administrativos emitidos por consejos o tribunales regidos por leyes especiales, competentes para resolver controversias en última instancia administrativa, solo pueden ser objeto de declaración de nulidad de oficio en sede administrativa por el propio consejo o tribunal con el acuerdo unánime de sus miembros. Esta atribución solo podrá ejercerse dentro del plazo de un año contado desde la fecha en que el acto es notificado al interesado. También procede que el titular de la entidad demande su nulidad en la vía de proceso contencioso administrativo, siempre que la demanda se interponga dentro de los tres años siguientes de notificada la resolución emitida por el consejo o tribunal. 
confuso cuando, por ejemplo, se advierte que en ocasiones un acto administrativo inválido puede surtir plenos efectos, o también cuando se verifica que un acto infractor de la ley no es inválido, en razón de que el vicio es irrelevante para el derecho.

La noción de validez del acto administrativo está directamente vinculada con el principio de legalidad. Un acto administrativo será válido en la medida que su generación se haya realizado de conformidad con el ordenamiento jurídico, lo que importa que todos los requisitos constitutivos para su emisión se configuren sin vicios trascendentes.

El artículo 3 de la LPAG establece que los requisitos de validez de los actos administrativos son cinco: (i) competencia, (ii) objeto o contenido, (iii) finalidad pública, (iv) motivación y (v) procedimiento regular ${ }^{4}$. La ley establece cómo debe configurarse cada uno de estos requisitos para que el acto administrativo sea considerado válido.

Ahora bien, cuando referimos que los requisitos del acto administrativo deben concurrir sin que se presenten vicios relevantes o graves de legalidad, ello es así porque el ordenamiento jurídico tolera la existencia de vicios no trascendentes respecto de los requisitos de validez del acto administrativo. En estos casos, prevalece la conservación del acto administrativo y no se sanciona su nulidad, sin perjuicio de la enmienda del mismo por parte de la autoridad emisora ${ }^{5}$.

4 LPAG. Artículo 3.- Requisitos de validez de los actos administrativos

Son requisitos de validez de los actos administrativos:

1. Competencia.- Ser emitido por el órgano facultado en razón de la materia, territorio, grado, tiempo o cuantía, a través de la autoridad regularmente nominada al momento del dictado y en caso de órganos colegiados, cumpliendo los requisitos de sesión, quorum y deliberación indispensables para su emisión.

2. Objeto o contenido.- Los actos administrativos deben expresar su respectivo objeto, de tal modo que pueda determinarse inequívocamente sus efectos jurídicos. Su contenido se ajustará a lo dispuesto en el ordenamiento jurídico, debiendo ser lícito, preciso, posible física y jurídicamente, y comprender las cuestiones surgidas de la motivación.

3. Finalidad pública.- Adecuarse a las finalidades de interés público asumidas por las normas que otorgan las facultades al órgano emisor, sin que pueda habilitársele a perseguir mediante el acto, aun encubiertamente, alguna finalidad, sea personal de la propia autoridad, a favor de un tercero, u otra finalidad pública distinta a la prevista en la ley. La ausencia de normas que indiquen los fines de una facultad no genera discrecionalidad.

4. Motivación.- El acto administrativo debe estar debidamente motivado en proporción al contenido y conforme al ordenamiento jurídico.

5. Procedimiento regular.- Antes de su emisión, el acto debe ser conformado mediante el cumplimiento del procedimiento administrativo previsto para su generación.

5 LPAG. Artículo 14.- Conservación del acto

14.1 Cuando el vicio del acto administrativo por el incumplimiento a sus elementos de validez no sea trascendente, prevalece la conservación del acto, procediéndose a su enmienda por la propia autoridad emisora.

14.2 Son actos administrativos afectados por vicios no trascendentes los siguientes:

14.2.1 El acto cuyo contenido sea impreciso o incongruente con las cuestiones surgidas en la motivación.

14.2.2 El acto emitido con una motivación insuficiente o parcial. 
La noción de conservación del acto administrativo produce una dicotomía en materia de nulidades administrativas: (i) los actos que contienen vicios trascendentes respecto de sus elementos configuradores se consideran inválidos y son susceptibles de ser declarados nulos; y (ii) los actos que contienen vicios intrascendentes respecto de sus elementos configuradores se consideran válidos y se conservan. Los segundos, pese a que formalmente pueden haber infringido el ordenamiento jurídico, no se consideran incompatibles per se con el principio de legalidad y, por ende, no se configuran como inválidos.

He aquí otra de las grandes diferencias entre la nulidad civil y la administrativa en el derecho peruano: nuestro ordenamiento administrativo general no contempla la figura de la anulabilidad de los actos administrativos. Los actos son válidos y compatibles con el sistema jurídico o, sencillamente, no lo son; no cabe la posibilidad de actos administrativos viciados con nulidad relativa y que se encuentren, por ende, sujetos a confirmación por parte de la Administración.

No se debe incurrir en el error frecuente de asociar la noción de conservación del acto administrativo con la anulabilidad. La conservación niega la existencia de la nulidad absoluta o relativa, toda vez que salvaguarda la validez del acto administrativo, en razón de que este se encuentra afectado solo por un vicio intrascendente que no resulta suficiente para considerarlo incompatible con el ordenamiento jurídico. Dicho vicio deberá ser enmendado de oficio por la Administración, pero en ningún caso importa una contravención relevante e insalvable al principio de legalidad. En buena cuenta, se hace prevalecer el cumplimiento de la finalidad del acto, sobre los formalismos que no inciden en su validez, en aplicación del principio de eficaciab.

14.2.3 El acto emitido con infracción a las formalidades no esenciales del procedimiento, considerando como tales aquellas cuya realización correcta no hubiera impedido o cambiado el sentido de la decisión final en aspectos importantes, o cuyo incumplimiento no afectare el debido proceso del administrado.

14.2.4 Cuando se concluya indudablemente de cualquier otro modo que el acto administrativo hubiese tenido el mismo contenido, de no haberse producido el vicio.

14.2.5 Aquellos emitidos con omisión de documentación no esencial.

14.3 No obstante la conservación del acto, subsiste la responsabilidad administrativa de quien emite el acto viciado, salvo que la enmienda se produzca sin pedido de parte y antes de su ejecución.

6 El principio de eficacia que rige el procedimiento administrativo se encuentra reconocido en el numeral 1.10 del artículo IV del "Título preliminar" de la LPAG, que dice lo siguiente:

Artículo IV.- Principios del procedimiento administrativo

1. El procedimiento administrativo se sustenta fundamentalmente en los siguientes principios, sin perjuicio de la vigencia de otros principios generales del derecho administrativo:

[...]

1.10. Principio de eficacia.- Los sujetos del procedimiento administrativo deben hacer prevalecer el cumplimiento de la finalidad del acto procedimental, sobre aquellos formalismos cuya realización no incida en su validez, no determinen aspectos importantes en la decisión final, no disminuyan las garantías del procedimiento, ni causen indefensión a los administrados. 
Asimismo, no se debe confundir la noción de invalidez del acto administrativo con la sanción que determina la cesación de su existencia y efectos. Esta última es la nulidad. Así, un acto administrativo inválido podrá permanecer surtiendo efectos jurídicos en tanto no se sancione su nulidad; e, incluso, puede ocurrir que, por el transcurso del tiempo, sea imposible jurídicamente que ello ocurra, lo que conlleva la aceptación por parte del sistema jurídico de un acto contrario a la legalidad. Esto ocurre cuando los actos inválidos son consentidos por los administrados al no ser impugnados dentro del plazo de ley; prescribe la facultad de la Administración para declarar la nulidad de oficio de tales actos administrativos; y caducan las acciones tendientes a declarar la nulidad de los actos administrativos en sede judicial ${ }^{7}$.

Ocuparnos de la invalidez nos obliga a pronunciarnos sobre la mal llamada "nulidad de pleno derecho", referida en el artículo 10 de la LPAG. Como sabemos, esta norma contempla los cuatro vicios del acto administrativo que causan su nulidad, literalmente, "de pleno derecho"8. Sin embargo, cuando se efectúa una interpretación sistemática de esta norma con relación a la integridad de la LPAG, se concluye indubitablemente que entre invalidez y nulidad no existe una relación causal necesaria y obligatoria. Como quiera que la propia LPAG ha previsto plazos perentorios para que los administrados interpongan los recursos impugnativos tendientes a perseguir la nulidad de los actos administrativos $y$, a su vez, ha contemplado también un plazo prescriptorio (dos años) para que la Administración declare la nulidad de oficio de sus propios actos, cabe la posibilidad de que los actos administrativos inválidos no sean declarados nulos debido al vencimiento de tales términos. De este modo, se ha preferido la seguridad jurídica frente a la legalidad.

En todos los supuestos de aplicación de este principio, la finalidad del acto que se privilegie sobre las formalidades no esenciales deberá ajustarse al marconormativo aplicable y su validez será una garantía de la finalidad pública que se busca satisfacer con la aplicación de este principio.

7 Como es sabido, los plazos que fija el TUO de la Ley 27548, Ley que Regula el Proceso Contencioso Administrativo, aprobado por el Decreto Supremo 011-2019-JUS, para interponer una demanda contencioso-administrativa cuya finalidad es la declaración de nulidad de un acto administrativo, son de caducidad. No obstante, no resulta inusual que los administrados recurran a acciones constitucionales, como el amparo, cuando un acto administrativo vulnera derechos constitucionales; mencionamos esto porque los plazos para interponer este tipo de acciones son de prescripción, conforme a lo previsto por el Código Procesal Constitucional.

8 LPAG. Artículo 10.- Causales de nulidad

Son vicios del acto administrativo, que causan su nulidad de pleno derecho, los siguientes:

1. La contravención a la Constitución, a las leyes o a las normas reglamentarias.

2. El defecto o la omisión de alguno de sus requisitos de validez, salvo que se presente alguno de los supuestos de conservación del acto a que se refiere el artículo 14.

3. Los actos expresos o los que resulten como consecuencia de la aprobación automática o por silencio administrativo positivo, por los que se adquiere facultades, o derechos, cuando son contrarios al ordenamiento jurídico, o cuando no se cumplen con los requisitos, documentación o trámites esenciales para su adquisición.

4. Los actos administrativos que sean constitutivos de infracción penal, o que se dicten como consecuencia de la misma. 
Lo primero que fluye de esta situación es que existirán actos administrativos que incurren en vicios de legalidad gravísimos y que podrán surtir plenos efectos, en razón de que fueron consentidos, o porque la potestad de la Administración para declarar su nulidad de oficio prescribió. En buena cuenta, para nuestra LPAG, los actos inválidos serán "tolerados" gracias al transcurso del tiempo. Esto ha hecho que algunos administrativistas, como Baca (2007), sostengan que la nulidad de pleno derecho que recoge la LPAG no es otra cosa que una mera anulabilidad.

En nuestra opinión, la mal llamada "nulidad de pleno derecho" prevista en la LPAG, artículo 10, no es tal, pero la regulación contenida en nuestra norma tampoco es conceptualizada como una anulabilidad. Es cierto que algunos ordenamientos administrativos comparados (por ejemplo, el de España) asocian los actos anulables con aquellos cuyos vicios de validez son subsanables y su revisión — sea a solicitud del administrado o ex officio- está sujeta a términos perentorios. En contrapartida, los actos nulos de pleno derecho serán aquellos que revisten vicios de especial gravedad y trascendencia, lo que justifica su anulación de oficio sin sujeción a un límite temporal; en otras palabras, es imprescriptible.

Santamaría Pastor (2004), comentando el ordenamiento administrativo español, refiere que la figura de la nulidad de oficio se caracteriza por dos efectos: (i) en primer lugar, los actos nulos de pleno derecho no son convalidables mediante la subsanación ulterior de los vicios que padezcan; y (ii), en segundo lugar, son sanables parcialmente por el transcurso del tiempo (imprescriptibilidad relativa). Respecto a esto último, precisa que existirá un efecto diverso según se trate de la impugnación de un acto en vía de recurso o revisión de oficio:

La impugnación de un acto nulo en vía de recurso se encuentra sometida a los mismos plazos de caducidad que la impugnación de los actos anulables, de tal forma que la ausencia de interposición del recurso en tiempo hábil los hace igualmente inatacables; en cambio, la revisión de oficio de los actos nulos puede hacerse en cualquier momento, sin sujeción a plazo alguno. (Santamaría Pastor, 2004, p. 138)

Según este autor, la figura de la nulidad de pleno derecho permite la revisión de oficio de los actos administrativos en cualquier momento, es decir, sin que medie plazo prescriptorio. Ciertamente, esto no ocurre en el ordenamiento administrativo peruano, que contempla un límite temporal (que hoy es de dos años) para que la Administración declare de oficio la nulidad de sus propios actos.

En el modelo administrativo peruano, la nulidad de los actos administrativos no está concebida como una de pleno derecho (imprescriptible) ${ }^{9}$, sino que se trata de una nulidad

9 Aunque el artículo 10 de la LPAG afirme ello de manera ostentosa. 
absoluta. La nulidad absoluta regulada en la LPAG no admite la convalidación del acto administrativo mediante la subsanación de los vicios de validez que este padezca, pues estos son trascendentes e incompatibles con la legalidad; sin embargo, si transcurre un plazo razonable sin que la invalidez del acto administrativo haya merecido una declaración de nulidad, entonces este se torna inmune o intangible a la revisión de oficio por parte de la Administración.

Al igual que en el derecho civil, la nulidad absoluta administrativa no es sinónimo de invalidez ipso iure o imprescriptible. Por el contrario, siempre se requerirá que la autoridad administrativa o jurisdiccional declare la nulidad y, lo más importante, el transcurso del tiempo generará que el acto administrativo inválido resista cualquier acción nulificante en su contra, lo que determina que su ilegalidad sea, finalmente, intangible en el ordenamiento jurídico. En este último estadio se presume, iure et de iure, que eliminar los efectos del acto administrativo inválido de manera retroactiva resulta más pernicioso para el sistema jurídico que mantenerlo vigente y eficaz; por lo que, transcurrido cierto plazo razonable, se privilegia la seguridad jurídica frente a la legalidad.

Es excesivo señalar que la figura de nulidad absoluta posibilita que el acto inválido sea sanado por el transcurso del tiempo, pues ello, en rigor, no ocurre, sino que simplemente existirá una tolerancia a la invalidez del mismo, en atención a la preferencia por la seguridad jurídica frente a la legalidad.

Esta circunstancia, tan particular en nuestro ordenamiento administrativo, hace necesario evaluar la incorporación en la LPAG, de manera positiva, de figuras jurídicas como la real nulidad de pleno derecho o la inexistencia para vicios de validez especialmente graves, pero como figuras residuales y excepcionales. Asimismo, coincidimos con quienes sostienen que la inexistencia es una figura que hoy tiene cabida en el ordenamiento jurídico administrativo peruano (Baca, 2007, p. 260), encontrando pleno sustento en la vigencia y aplicación de principios generales del derecho administrativo como los de legalidad, ejercicio legítimo del poder y eficacia, así como en la propia noción garantista de seguridad jurídica, ya que no hay nada más inseguro que conferirle valor legal a hechos ilegales o imposibles jurídicos.

En efecto, no resulta compatible con el derecho reconocer la existencia de actuaciones con severos vicios de legalidad y que jamás serán compatibles con el ordenamiento por ser imposibles jurídicamente, como es el caso de un acto administrativo emitido por una entidad territorialmente incompetente o la adjudicación a particulares de bienes públicos inalienables; casos como estos no deben ser tolerados por el derecho en mérito al transcurso del tiempo y simplemente corresponde considerarlos como inexistentes. La aplicación de la figura de la inexistencia debe ser excepcional y extraordinaria, razón por la cual urge su regulación positiva; pero, en tanto ello no ocurra, corresponderá a los jueces y magistrados desarrollar su contenido y alcance. Lamentablemente, la emisión 
del Decreto Legislativo 1272, que introdujo diversas y potentes modificaciones a la LPAG, fue una oportunidad desaprovechada para llenar este vacío legal.

No obstante, se debe resaltar que el Decreto Legislativo 1272 ha incorporado entre sus modificaciones un supuesto de revocación del acto administrativo por incompatibilidad con el ordenamiento jurídico, que si bien nada tiene que ver con la figura de la inexistencia, cuando menos permite al sistema legal tener una salida para expulsar a los actos administrativos inválidos que fueron consentidos por los administrados, o respecto de los cuales venció el plazo para que la Administración los declare nulos de oficio.

Este nuevo supuesto está previsto en el numeral 212.4 del artículo 212 de la LPAG, el cual señala que cabe la revocación de actos administrativos, con efectos a futuro, "cuando se trate de un acto contrario al ordenamiento jurídico que cause agravio o perjudique la situación jurídica del administrado, siempre que no se genere perjuicios a terceros". Como se aprecia, este supuesto de revocación permite que los efectos de un acto administrativo ilegal cesen a futuro (ex nunc), siempre que se cause agravio o se perjudique la situación jurídica del administrado. Nótese que el supuesto de hecho no abarca la afectación a la Administración o un agravio al interés público, por lo que los actos ilegales que afectan exclusivamente a estos últimos, en rigor, no podrán ser revocados invocando esta causal.

\section{NULIDAD DE OFICIO COMO MANIFESTACIÓN DE LA AUTOTUTELA ADMINISTRATIVA}

La nulidad de oficio de los actos administrativos constituye una manifestación del poder de autotutela de la Administración. El régimen de autotutela se materializa en una posición de privilegio de la Administración frente a los administrados en lo que respecta a la alteración y ejecución de sus actos y actuaciones, lo cual le permite prescindir de la tutela jurisdiccional para tales fines.

Cuando los particulares enfrentan un conflicto entre sí, no pueden asumir la justicia por mano propia, sino que, por principio, deben buscar a un tercero atribuido con función jurisdiccional para que imparta una solución a la controversia ajustada a derecho (heterotutela). Tradicionalmente, los jueces monopolizaban la función jurisdiccional, pero hoy esto ya no así, gracias a la consolidación del arbitraje. Esto último no ocurre en el caso de la Administración que, por su condición de poder público, puede adoptar decisiones y actuaciones que afectan la esfera jurídica de los administrados para tutelar su propia situación jurídica, de manera previa a la intervención de un juez.

La prescindencia de intervención jurisdiccional para tutelar su situación jurídica y la variación del statu quo de las relaciones que mantiene con los administrados no significan que la Administración no esté sometida a control jurisdiccional, sino que goza de las siguientes potestades: (i) efectivizar la ejecución de sus actos de manera 
directa e inmediata, incluso a través de medios de ejecución forzosa (ejecutoriedad); (ii) imponer directamente sanciones a los administrados que infringen el ordenamiento administrativo o incumplen con obligaciones y mandatos frente a ella; (iii) establecer una vía administrativa previa a los particulares que le posibilita revisar a ella misma los reclamos respecto de actos que ha dictado, antes de que aquellos puedan acceder a los tribunales; y (iv) revisar de oficio sus propios actos (vía rectificación de errores, nulidad o revocación). Santamaría Pastor (2004) sostiene con relación a la posición de autotutela:

La Administración no precisa de la colaboración judicial para hacer declaraciones de derechos que alteren per se las situaciones jurídicas o estados posesorios (tutela declarativa), ni para ejecutar coactivamente tales declaraciones (tutela ejecutiva): la autotutela supone que, por regla general, puede realizar por sí misma uno y otro tipo de actividades. (p. 93)

Así, a diferencia de los administrados, que para lograr la nulidad de un acto administrativo deben someterse a la misma Administración para que esta evalúe la legalidad de su propia actuación y, en caso de no encontrar respuesta satisfactoria en la vía administrativa, gozan del derecho a formular su pretensión de nulidad ante un juez contencioso-administrativo, la Administración puede declarar la nulidad de oficio de sus propios actos administrativos sin necesidad de recurrir a un tercero o, lo que es lo mismo, confiriéndose tutela a sí misma.

De este modo, la Administración tiene el poder de evaluar la legalidad de los actos administrativos que emitió y anular aquellos que tienen vicios trascendentes que afectan su validez, sin importar que estos hayan estado generando efectos e incidiendo en la esfera jurídica de los administrados. Naturalmente, para aquellos administrados que han visto habilitado el ejercicio de derechos o han adquirido estos en virtud de un acto administrativo anulado por la propia Administración que los dictó, la sensación de inseguridad jurídica es intensa, sobre todo porque no ha existido una autoridad jurisdiccional que medie y decida sobre dicha nulidad. Es más, la regla general es que recién podrán recurrir al Poder Judicial una vez que se haya consumado la nulidad del acto administrativo, a efectos de intentar revertir tal situación.

Una persona que goza de una autorización administrativa, una certificación, un registro o cualquier otro acto que lo beneficie, y que es ajena a la esfera del derecho administrativo, se sorprende sobremanera al conocer los alcances de esta potestad de la Administración, y más aún cuando sabe que dicha prerrogativa está sujeta a un plazo de prescripción de dos años.

Por ello, la nulidad de oficio de los actos administrativos debe ser una medida extraordinaria y que debe efectivizarse previo procedimiento administrativo que garantice el derecho de defensa de los administrados, lo que implica la real y efectiva evaluación de los argumentos y medios de pruebas aportados por estos (conforme a la 
normativa vigente, dicho plazo no puede ser menor de cinco días hábiles). Dada su naturaleza de poder público, la Administración goza de este privilegio de autotutela frente a los administrados, pero en la medida que su materialización puede significar la eliminación, limitación o afectación de derechos e intereses, su ejercicio debe realizarse en estricta sujeción a los principios de legalidad, debido procedimiento, eficacia, confianza legítima y ejercicio legítimo del poder.

\section{PRESUPUESTOS PARA LA DECLARACIÓN DE LA NULIDAD DE OFICIO DE UN ACTO ADMINISTRATIVO}

De conformidad con el artículo 213 de la LPAG, en cualquiera de los casos enumerados en el artículo 10 del mismo cuerpo normativo puede declararse de oficio la nulidad de los actos administrativos, aun cuando hayan quedado firmes, siempre que agravien el interés público o lesionen derechos fundamentales.

En ese sentido, para que la Administración revise de oficio la validez de sus propios actos administrativos no basta que estos (i) contravengan la Constitución, las leyes o las normas reglamentarias; (ii) presenten un defecto u omisión de alguno o algunos de sus requisitos de validez; (iii) sean actos expresos o resulten de una aprobación automática o por silencio administrativo positivo, por los que se adquieren derechos o facultades contrarios al ordenamiento jurídico, o cuando no se cumple con los requisitos, documentos o trámites esenciales para su adquisición; o (iv) sean constitutivos de infracción penal o se hayan dictado como consecuencia de la misma. Además, se debe verificar que haya un agravio concreto y real al interés público o una lesión a algún derecho fundamental. En ese sentido, la existencia de los vicios previstos en el artículo 10 de la LPAG - que hemos referido- constituye causa suficiente para declarar la nulidad de los actos en el marco de una impugnación administrativa por parte de los administrados o en caso de que la declaración de nulidad sea conocida por un juez; pero no lo es tratándose del ejercicio de la prerrogativa de autotutela de nulidad de oficio que ostenta la Administración.

El agravio al interés público comúnmente se considera como un concepto jurídico indeterminado, pero está lejos de serlo. En todo caso, advertimos que, para efectos de la revisión de oficio de la validez de los actos administrativos, la mera vulneración al ordenamiento jurídico no constituye sinónimo de agravio al interés público; y, precisamente por eso, el artículo 213 de la LPAG lo ha contemplado como un requisito adicional a las causales de nulidad previstas en el artículo 10, entre las cuales se encuentra la concerniente a la contravención a la Constitución, a las leyes o a las normas reglamentarias.

En este punto, surge una duda válida: si no existe un agravio al interés público o no se lesionan derechos fundamentales, ¿la Administración podría formular la nulidad de sus propios actos ante el Poder Judicial directamente a través de una demanda 
contencioso-administrativa? En nuestra opinión, la respuesta debería ser negativa. Esto se desprende de lo previsto en el segundo párrafo del artículo 13 del TUO de la Ley 27584, Ley que Regula el Proceso Contencioso Administrativo, aprobado por el Decreto Supremo 011-2019-JUS, que a la letra dispone lo siguiente:

También tiene legitimidad para obrar activa la entidad pública facultada por ley para impugnar cualquier actuación administrativa que declare derechos subjetivos; previa expedición de la resolución motivada en la que se identifique el agravio que aquella produce a la legalidad administrativa y al interés público, y siempre que haya vencido el plazo para que la entidad que expidió el acto declare su nulidad de oficio en sede administrativa.

Como se advierte en la norma citada, si bien cabe la posibilidad legal de que una entidad pública pueda demandar la nulidad de sus propios actos administrativos en un proceso contencioso-administrativo, ejerciendo la acción de lesividad, para ello debe cumplir ineludiblemente con un presupuesto procesal, esencial e indispensable, que consiste en la emisión de la resolución motivada en la que se identifique el agravio que el acto en cuestión produce a la legalidad administrativa y al interés público. En ese sentido, si no existe una resolución administrativa en la cual la Administración, previamente, identifique y justifique en qué consiste el agravio al interés público o la lesión a derechos fundamentales -en tanto ello supone una violación a la legalidad administrativa-, entonces, no cabe posibilidad de incoar una demanda peticionando la nulidad de sus actos administrativos. Al respecto, Huapaya (2006) sostiene:

[...] la resolución de agravio o que declara la lesividad es un presupuesto de primer orden, puesto que centra o determina el fundamento mediante el cual se solicita la tutela jurisdiccional con la finalidad de declarar la nulidad del acto considerado lesivo. En tal sentido, es un presupuesto procesal imprescindible en orden de constituir adecuadamente la relación jurídico-procesal que se manifiesta a través del proceso de lesividad. (pp. 894-895)

En ese sentido, si no existe motivación expresa y concreta sobre agravio al interés público o lesión a los derechos fundamentales, no cabe la nulidad de oficio de los actos administrativos, ni tampoco la interposición de una acción de lesividad.

\section{PLAZO PARA DECLARAR LA NULIDAD DE OFICIO DE LOS ACTOS ADMINISTRATIVOS}

La potestad de declarar de oficio la nulidad de los actos administrativos presupone una delimitación restrictiva al derecho de igualdad ante la ley de los particulares con relación a la Administración, la que se justifica, principalmente, en la salvaguarda del principio de legalidad. En efecto, si la Administración determina, vía fiscalización posterior de su propia actividad, que una decisión suya ha sido emitida vulnerando gravemente la legalidad, corresponde tomar acción al respecto y revertir dicha decisión, de oficio, sin necesidad de recurrir a un juez. 
En algunas legislaciones comparadas (por ejemplo, la de España) que contemplan la nulidad de pleno derecho en su real dimensión, la revisión de oficio de los actos inválidos puede hacerse en cualquier momento, es decir, de manera indefinida ${ }^{10}$. Sin embargo, esto no ocurre en nuestro derecho, en el cual existe un plazo perentorio para que la Administración declare la nulidad de sus propios actos. Conforme al numeral 213.3 del artículo 213 de la LPAG — según su texto modificado por el Decreto Legislativo 1272-. este plazo es de dos años, contados a partir de la fecha en que ha quedado consentido el acto administrativo"1. Cabe recordar que el texto original de la LPAG preceptuaba que la facultad para declarar la nulidad de oficio prescribía al año de producido el consentimiento del acto administrativo.

En nuestra opinión, un plazo de dos años para declarar la nulidad de oficio de actos administrativos favorables a los administrados resulta excesivo, por lo que constituye una regulación que afecta la seguridad jurídica y amplía la brecha de desigualdad en la relación de poder que existe entre la Administración y los administrados; máxime si nuestra legislación contempla plazos breves para que estos últimos puedan plantear la nulidad de los actos administrativos mediante recursos impugnativos administrativos o mediante la demanda contencioso-administrativa.

En efecto, cuando el administrado es quien solicita dicha revisión por los mismos motivos, los plazos que tiene para hacerlo son cortos y perentorios. Como sabemos, para formular la nulidad de un acto administrativo, el administrado debe hacerlo por medio de los recursos administrativos correspondientes (numeral 11.1 del artículo 11 de la LPAG) dentro de un plazo de quince días hábiles perentorios (artículo 21 de la LPAG), computado, como regla general, a partir del día hábil siguiente de aquel en que se practique la

10 Esta postura tradicional y aún imperante de la imprescriptibilidad de la revisión de oficio de los actos nulos de pleno derecho viene siendo tamizada de un tiempo a esta parte. Así, Sánchez Morón (2013) refiere que "la expresión en cualquier momento no significa tampoco que las facultades de revisión de oficio carezcan de todo límite en el tiempo. Es significativo, por ejemplo, que, a diferencia de esa regla, la jurisprudencia comunitaria europea recalque que las potestades revocatorias de actos nulos de pleno derecho -inexistentes, en la terminología comunitaria- de las instituciones de la Unión Europea solo pueden ejercerse durante un plazo razonable (SSTJUE del 12 de julio de 1962, Hoogovens; 13 de junio de 1965, Lemmerz-Werke; 20 de junio de 1991, Cargill, etc.). En nuestro derecho, el artículo 106 LRJPAC dispone, no obstante, que las facultades de revisión no podrán ser ejercitadas cuando, entre otras causas, por el tiempo transcurrido, su ejercicio resulte contrario a la equidad, la buena fe, al derecho de los particulares o a las leyes; o a la confianza legítima, podríamos añadir. La interpretación y aplicación de este artículo 106 debe también llevar a limitar la posibilidad de ejercicio de la potestad de revisión de oficio a un plazo razonable, que puede variar en función de las circunstancias" (p. 570).

11 El numeral 213.3 del artículo 213 de la LPAG señala lo siguiente: "213.3. La facultad para declarar la nulidad de oficio de los actos administrativos prescribe en el plazo de dos (2) años, contado a partir de la fecha en que hayan quedado consentidos, o contado a partir de la notificación a la autoridad administrativa de la sentencia penal condenatoria firme, en lo referido a la nulidad de los actos previstos en el numeral 4 del artículo 10". 
notificación del acto administrativo ${ }^{12}$. Por su parte, el plazo para que un administrado pueda plantear una demanda contencioso-administrativa cuya pretensión sea la declaración de nulidad total o parcial de un acto administrativo es de tres meses, contados desde el conocimiento o notificación de la actuación impugnada, lo que ocurra primero ${ }^{13}$.

Un supuesto especial para el cómputo del plazo prescriptorio de la anulación de oficio del acto administrativo es el relativo al caso de los actos constitutivos de infracción penal, o que se dicten como consecuencia de la misma. En esta situación, dicho término se computa a partir de la notificación a la autoridad administrativa de la sentencia penal condenatoria firme por parte del Poder Judicial, de acuerdo con lo previsto en el numeral 213.3 del artículo 213 de la LPAG. Esta regla particular se explica en que no cabe iniciar debido a que no resulta razonable.

\section{CUESTIONES PROCEDIMENTALES}

Es importante tener presentes las cuestiones de orden procedimental que rigen la nulidad de oficio.

\section{Procedimiento regular}

La revisión de oficio de la validez de un acto administrativo favorable al administrado requiere ser instruida y resuelta en el marco de un procedimiento administrativo. Se debe distinguir entre dos situaciones procedimentales que pueden dar mérito a una nulidad de oficio: (i) la invalidación de un acto administrativo no firme en el seno de un expediente administrativo en curso, en particular, a propósito del trámite de un procedimiento recursal; y (ii) la invalidación de un acto administrativo firme en un procedimiento invalidatorio autónomo iniciado de oficio por la Administración.

El escenario (i) se presenta cuando, a propósito de un recurso administrativo, la autoridad toma conocimiento de la existencia de un vicio que afecta la validez del acto administrativo y que no ha sido objeto de impugnación por parte del administrado. En este caso, en respeto a los principios de debido procedimiento y buena fe procedimental,

12 La regla del inicio del cómputo del plazo está prevista, en todo su alcance, en el artículo 142 de la LPAG que establece, a la letra, lo siguiente:

Artículo 142.- Inicio de cómputo

142.1 El plazo expresado en días es contado a partir del día hábil siguiente de aquel en que se practique la notificación o la publicación del acto, salvo que este señale una fecha posterior, o que sea necesario efectuar publicaciones sucesivas, en cuyo caso el cómputo es iniciado a partir de la última.

142.2 El plazo expresado en meses o años es contado a partir de la notificación o de la publicación del respectivo acto, salvo que este disponga fecha posterior.

13 Según el artículo 18, inciso 1, del TUO de la Ley 27584, Ley que Regula el Proceso Contencioso Administrativo, aprobado por el Decreto Supremo 011-2019-JUS. 
la autoridad deberá brindar al administrado la posibilidad de ejercer su derecho de defensa y, por ello, previamente a la emisión de su pronunciamiento, debe conferirle el derecho de audiencia y descargo respecto de las eventuales causas que motivan la invalidez del acto.

No cabe duda de que, en concordancia con los principios de legalidad e impulso de oficio, la autoridad administrativa está facultada para revisar de oficio la validez integral de un acto administrativo que es puesto a su conocimiento, sin limitarse a la verificación de la legalidad de aquello que ha sido objeto del ejercicio del derecho de contradicción del administrado. Sin embargo, no se encontrará conforme a derecho la emisión de un acto definitivo dictado en el marco de un procedimiento recursal que declare la nulidad del acto impugnado por causas distintas de las peticionadas y de los agravios expresados en el recurso administrativo respectivo, sin que se haya otorgado al administrado la posibilidad de expresar sus argumentos de defensa y ofrezca sus medios de prueba para estos.

La situación (ii) ocurre en los casos de revisión de oficio de la validez de actos administrativos firmes, respecto de los cuales ya no cabe impugnación en sede administrativa y, por tanto, el procedimiento administrativo del cual emanaron ya se encuentra concluido. En estos casos, tratándose de un acto administrativo favorable al administrado, se deberá iniciar un nuevo procedimiento administrativo en el cual se realizarán actuaciones postulatorias, de instrucción y decisorias que servirán para determinar si cabe o no declarar la nulidad del acto administrativo en cuestión.

En este procedimiento invalidatorio autónomo, se deberá notificar al administrado la causal de nulidad en la que se encontraría inmerso el acto, así como las razones que causan agravio el interés público o lesionan los derechos fundamentales. Esto se deriva de una interpretación lógica, sistemática y teleológica de los artículos 10 y 213 de la LPAG. Asimismo, se deberá conferir al administrado un plazo razonable para que pueda ejercer su derecho de defensa, presentando sus descargos, formulando mecanismos de defensa (por ejemplo, alegación de la prescripción) y aportando los medios de prueba que considere pertinentes. El plazo mínimo que establece la LPAG para estos efectos es de cinco días hábiles, de acuerdo con el numeral 213.2 de su artículo 213.

\section{Competencia}

La nulidad de oficio del acto administrativo es declarada por el órgano superior jerárquico de aquel que emitió el acto inválido ${ }^{14}$. Esta regla constituye un mecanismo de control interno de la propia Administración, porque (i), de un lado, permite al superior jerárquico controlar las actuaciones ilegales de los órganos inferiores, lo que es una

14 Según el numeral 11.2 del artículo 11 y el numeral 213.2 del artículo 213 de la LPAG. 
manifestación del principio de jerarquía que estructura la Administración Pública; y (ii), de otro lado, obliga al órgano emisor a realizar un análisis idóneo y objetivo sobre la legalidad de sus propios actos, así como de la existencia de un agravio actual y real al interés público o una lesión a derechos fundamentales, toda vez que el subalterno deberá elevar los actuados al superior jerárquico y pondría en evidencia su actuación ilegal para que este la evalúe y declare su nulidad. Respecto a esto último, cabe señalar que, al declarar la nulidad del acto, la autoridad superior deberá disponer lo conveniente para hacer efectiva la responsabilidad del órgano subalterno en caso de que se evidencie ilegalidad manifiesta ${ }^{15}$.

Se debe tener presente que la responsabilidad del emisor del acto inválido será más grave si la facultad para declarar su nulidad ex officio prescribe y se torna imposible invalidarlo en sede administrativa por el transcurso del tiempo. Por esta razón, existe un incentivo para que el responsable del acto viciado busque remediar la ilegalidad recurriendo al superior jerárquico. De este modo, la regla competencial en virtud de la cual corresponde al superior jerárquico declarar la nulidad de oficio de los actos administrativos importa un límite interno a la arbitrariedad para la Administración.

La excepción a esta regla se configura cuando la autoridad administrativa que emitió el acto objeto de invalidez no está sometida a subordinación jerárquica. En este caso, la nulidad de oficio deberá ser declarada por el mismo órgano emisor del acto que se invalida. De este modo, ante la ausencia de una revisión jerárquica en el interior de la propia Administración, se privilegia la autotutela administrativa y la salvaguarda del principio de legalidad frente a la alternativa de la revisión vía recurso de lesividad ante el Poder Judicial.

\section{Contradicción}

De acuerdo con el literal d) del numeral 228.2 de la LPAG $^{16}$, los actos administrativos que declaran la nulidad de oficio de otros agotan la vía administrativa; esto es, causan estado. Siendo esto así, la regla general es que la contradicción del acto anulatorio de oficio se formule a través de la demanda contencioso-administrativa tramitada ante el Poder Judicial.

No obstante, se debe tener presente que la invalidación de oficio de un acto administrativo firme requiere de la tramitación de procedimiento regular previo, en el cual el administrado pueda ejercer su derecho de defensa. Este procedimiento será autónomo

15 Ello de acuerdo con el numeral 11.3 del artículo 11 de la LPAG.

16 El texto del numeral 228.2 del artículo 228 de la LPAG dice: "228.2 Son actos que agotan la vía administrativa: [...] d) El acto que declara la nulidad o revoca otros actos administrativos en los casos a que se refieren los artículos 213 y $214 "$. 
respecto del que dio origen al acto que se busca invalidar - el primero concluyó con la emisión de un acto administrativo definitivo y firme-, y se estructurará en una única vía administrativa, en razón de que, como hemos referido, los actos anulatorios de oficio agotan la vía administrativa.

Siendo esto así, cabe preguntarse si la regla contenida en el literal a) del numeral 228.2 del artículo 228 de la LPAG, relativa a la posibilidad de interponer recurso de reconsideración contra actos que no son susceptibles de impugnación ante una autoridad jerárquicamente superior en la vía administrativa, también resulta aplicable a los actos anulatorios de oficio. Al respecto, la norma en cuestión dispone que agota la vía administrativa

[...] el acto respecto del cual no proceda legalmente impugnación ante una autoridad u órgano jerárquicamente superior en la vía administrativa o cuando se produzca silencio administrativo positivo, salvo que el interesado opte por interponer recurso de reconsideración, en cuyo caso la resolución que se expida o el silencio administrativo producido con motivo de dicho recurso impugnativo agota la vía administrativa.

En nuestra opinión, la regla del literal d) del numeral 228.2 de la LPAG, que determina que los actos administrativos que declaran la nulidad de oficio de otros agotan la vía administrativa, no excluye la aplicación de la posibilidad de interponer recurso de reconsideración, conforme al literal a) del mismo numeral. El hecho de que se determine que el acto anulatorio de oficio causa estado no enerva la posibilidad de que el administrado interponga, opcionalmente, un recurso de reconsideración, como lo establece la regla contenida en el literal a) del numeral 228.2 para todos los actos administrativos emanados de procedimientos administrativos de instancia única.

Nuestra interpretación de la norma es sistemática con el artículo 219 de la LPAG que posibilita, excepcionalmente, interponer recurso de reconsideración contra actos emitidos en procedimientos de única instancia administrativa, sin necesidad de aportar prueba nueva ${ }^{17}$. Morón (2020), sobre este particular, refiere:

De suyo en este caso, el administrado tendría agotada la vía administrativa por la emisión de este acto, por no haber instancia superior ante la cual plantear alguna apelación. Pero la norma faculta al administrado, igualmente con carácter potestativo, para interponer este recurso ante la propia autoridad emisora, para intentar revertir la situación aun en la sede administrativa, como un mecanismo facultativo para evitar el costo y la demora del proceso contencioso-administrativo.

17 El texto del artículo 219 de la LPAG señala lo siguiente: "El recurso de reconsideración se interpondrá ante el mismo órgano que dictó el primer acto que es materia de la impugnación y deberá sustentarse en nueva prueba. En los casos de actos administrativos emitidos por órganos que constituyen única instancia no se requiere nueva prueba. Este recurso opcional y su no interposición no impide el ejercicio del recurso de apelación". 
Obviamente, si el administrado opta por este recurso de reconsideración extraordinario, no requerirá nueva prueba y deberá esperar la decisión final para poder judicializar el caso. (Vol. II, p. 219)

De otro lado, cabe mencionar los alcances del numeral 213.2 del artículo 213 de la LPAG, que contempla la posibilidad de que, al declarar la nulidad de oficio, la autoridad pueda resolver sobre el fondo del asunto en caso de contar con elementos suficientes para ello; y, si ello no fuese posible, disponer la reposición del procedimiento administrativo al momento en que se produjo el vicio, anulando con ello todos los actos de trámite y definitivos que sucedieron con posterioridad al vicio (efectos reactivos de la nulidad).

Sobre este particular, debemos tener presente que, si bien el acto invalidatorio de oficio agota la vía administrativa, ello no enerva los efectos retroactivos de la nulidad; por eso, sin perjuicio de que el administrado tenga abierta la puerta del proceso contenciosoadministrativo para cuestionar la validez de dicha actuación, corresponderá reponer el procedimiento al momento en que ocurrió el vicio para que se emita un nuevo pronunciamiento conforme a derecho, salvo que el acto viciado se hubiera consumado, o bien sea imposible retrotraer sus efectos, lo que derivará en la responsabilidad del emisor y, eventualmente, la indemnización para el perjudicado, de acuerdo con el numeral 12.3 del artículo 12 de la LPAG.

Lo que queda claro es que el administrado no podrá recurrir a un recurso de apelación para que un superior jerárquico pueda revisar el acto anulatorio de oficio, sino que corresponde que contradiga dicha decisión en el proceso contencioso-administrativo, salvo la regla excepcional del recurso de reconsideración antes expuesta. Esa es la consecuencia natural de que un acto administrativo cause estado.

Ocupémonos ahora del supuesto de reconsideración regulado en el numeral 213.2 del artículo 213 de la LPAG, el cual se refiere al supuesto en el que la autoridad decide anular de oficio un acto administrativo y, en atención a que cuenta con los elementos de juicio suficientes, resuelve sobre el fondo del asunto. Sobre este particular, la norma señala literalmente lo siguiente: "En este caso, este extremo solo puede ser objeto de reconsideración". Esta norma es concordante con el literal d) del numeral 228.2 de la LPAG, que determina que el acto anulatorio de oficio agota la vía administrativa, no siendo posible interponer un recurso impugnativo que pueda ser conocido por un superior jerárquico, como es el caso del recurso de apelación.

Es preciso señalar que la norma no tiene por objeto restringir la interposición del recurso de reconsideración solo al acto o extremo del acto que resuelve el fondo del asunto, sino que tiene por finalidad dejar en claro que no cabe interposición de apelación. Esa debe ser la interpretación de este precepto, pues lo contrario sería limitar. 


\section{EL SUPUESTO PARTICULAR DE LOS TRIBUNALES ADMINISTRATIVOS}

La LPAG, en el texto original del numeral 202.3 de su artículo 202, establecía lo siguiente:

Los actos administrativos emitidos por consejos o tribunales regidos por leyes especiales, competentes para resolver controversias en última instancia administrativa, no pueden ser objeto de declaración de nulidad de oficio. Solo procede demandar su nulidad ante el Poder Judicial, vía el proceso contenciosoadministrativo, siempre que la demanda se interponga dentro de los tres años siguientes a contar desde la fecha en que el acto quedó firme ${ }^{18}$.

Como se aprecia, la LPAG inicialmente proscribía la posibilidad de que un tribunal administrativo que había resuelto una controversia entre administrados -en el marco de un procedimiento trilateral- revise de oficio sus decisiones; ello con la finalidad de evitar que, luego de existir un pronunciamiento firme y que hubiese causado estado, el propio colegiado lo anule a su sola discreción, reabra el caso y, eventualmente, cambie el sentido de su decisión original. Claramente, el legislador optó por la seguridad jurídica frente a la legalidad.

No obstante, mediante el Decreto Legislativo 1029, primero, y el Decreto Legislativo 1452, después, se modificó dicha norma legal, hoy contenida en el numeral 213.5 del artículo 213 de la LPAG con el siguiente texto:

Los actos administrativos emitidos por consejos o tribunales regidos por leyes especiales, competentes para resolver controversias en última instancia administrativa, solo pueden ser objeto de declaración de nulidad de oficio en sede administrativa por el propio consejo o tribunal con el acuerdo unánime de sus miembros. Esta atribución solo puede ejercerse dentro del plazo de dos (2) años contados desde la fecha en que el acto haya quedado consentido. También procede que el titular de la entidad demande su nulidad en la vía de proceso contencioso administrativo, siempre que la demanda se interponga dentro de los tres años siguientes de notificada la resolución emitida por el consejo o tribunal.

La citada norma evidencia un cambio radical de la postura inicialmente contemplada por el legislador, aunque restringida a los consejos o tribunales regidos por leyes especiales. En estos casos, los tribunales administrativos podrán anular de oficio el acto administrativo firme y que causó estado si cuentan con el acuerdo unánime de todos sus

18 El numeral 202.5 del artículo 202 de la LPAG (hoy numeral 213.5) fue inicialmente modificado por el artículo 1 del Decreto Legislativo 1029, cuyo texto era el siguiente: "202.5 Los actos administrativos emitidos por consejos o tribunales regidos por leyes especiales, competentes para resolver controversias en última instancia administrativa, solo pueden ser objeto de declaración de nulidad de oficio en sede administrativa por el propio consejo o tribunal con el acuerdo unánime de sus miembros. Esta atribución solo podrá ejercerse dentro del plazo de un año contado desde la fecha en que el acto es notificado al interesado. También procede que el titular de la entidad demande su nulidad en la vía de proceso contencioso administrativo, siempre que la demanda se interponga dentro de los tres años siguientes de notificada la resolución emitida por el consejo o tribunal". 
miembros. Como resulta evidente, deberá mediar un procedimiento administrativo en el que se confiera derecho de defensa a los administrados, así como deberá sustentarse la existencia de un agravio al interés público o una lesión a derechos fundamentales.

Cabe señalar que la modificación introducida por el Decreto Legislativo 1029 disponía que la nulidad de oficio podía ejercerse dentro del plazo de un año contado desde la fecha en que el acto fue notificado al interesado. Este plazo fue ampliado por el Decreto Legislativo 1452, estableciéndose un periodo de dos años para sancionar la nulidad de oficio en este supuesto especial, contado desde la fecha en que el acto haya quedado consentido.

Una cuestión por dilucidar, producto de este último cambio normativo, es a partir de qué momento se considera que un acto administrativo, emitido por un consejo o tribunal que ha resuelto una controversia en última instancia administrativa, ha quedado consentido. Ciertamente, el acto definitivo que se emite en última instancia administrativa causa estado, agotando la vía administrativa, pero no es sinónimo de acto consentido. En primer término, dicho acto devendrá en consentido y, a su vez, firme si no se recurre a la vía judicial para impugnar su validez (demanda contencioso-administrativa). Pero también será posible que el acto administrativo se torne en consentido debido a la actuación positiva del administrado, quien ejecuta el acto sin objetarlo o expresar reserva alguna; todo lo contrario, goza y acepta sus efectos.

Ahora bien, en el caso del acto definitivo consentido y firme se tendrá una certeza y objetividad sobre el momento en que se empieza a computar el plazo de dos años para que un tribunal administrativo pueda declarar la nulidad de oficio, ya que ello será verificable gracias a la notificación del acto que agota la vía administrativa. No ocurrirá lo mismo con el acto consentido por una actuación positiva y espontánea del administrado, ya que muchas veces será difícil tener certeza exacta de cuándo ocurrió ello, siendo necesaria la probanza de dicha situación.

\section{EL PROCESO CONTENCIOSO-ADMINISTRATIVO DE LESIVIDAD}

Vencido el plazo legal para que la Administración pueda declarar la nulidad de oficio de sus propios actos en sede administrativa, podrá interponer un proceso contenciosoadministrativo de lesividad, comúnmente conocido como acción de lesividad, con la finalidad de que se declare la nulidad de sus propios actos en sede judicial. En este proceso, la legitimidad activa recae en la entidad emisora del acto administrativo cuya nulidad se pretende, mientras que la legitimidad para obrar pasiva corresponderá a quien o quienes se vean afectados con dicha pretensión.

Una nota destacable sobre el proceso de lesividad es que se trata de una acción que solamente se podrá interponer en la medida en que haya vencido el plazo para poder 
declarar la nulidad de oficio, previa expedición de resolución motivada en la que se identifique el agravio a la legalidad y al interés público, conforme a lo previsto en el segundo párrafo artículo 13 del TUO de la Ley 27584, Ley que Regula el Proceso Contencioso Administrativo, aprobado por el Decreto Supremo 011-2019-JUS ${ }^{19}$. Consideramos que una interpretación sistemática de esta norma y el artículo 213 de la LPAG habilitan la posibilidad de interponer la acción de lesividad en el supuesto de que el acto a invalidar lesione derechos fundamentales.

Una delimitación clara impuesta por el artículo 13 del TUO de la Ley 27584 consiste en que el proceso de lesividad tiene por objeto la pretensión de nulidad de actos administrativos que declaren derechos subjetivos a los administrados. Para autores como Morón (2020), esta norma posibilita la pretensión de nulidad contra actos que otorgan o reconocen derechos e intereses a los administrados (vol. II, p. 171). Más específicamente, este autor señala que se debe entender por

[...] actos declarativos de derechos subjetivos aquellos que la doctrina reconoce como favorables a la esfera jurídica del destinatario del acto, creando un derecho, una facultad, o una posición de ventaja o beneficio, suprimiendo una limitación o desventaja, etcétera, como, por ejemplo, los actos conformadores o ampliatorios: la admisión, la autorización, la licencia, los permisos, la concesión, etcétera. Esta apreciación de favorabilidad también comprende aquellos en que el acto bifronte o de dos efectos, por ser también dos los destinatarios. (Morón, 2015, p. 231)

Otro aspecto relevante es que el proceso de lesividad se puede formular contra actos administrativos firmes, sea que estos hayan agotado o no la vía administrativa. Por ejemplo, los actos administrativos que no han agotado la vía administrativa, pero que tienen la calidad de firmes y consentidos por los administrados, en razón de que constituyen o declaran derechos o intereses en favor de estos, podrán ser objeto de una pretensión de nulidad en un proceso de lesividad, si estos se encuentran inmersos en una causal de nulidad prevista en el artículo 10 de la LPAG y, adicionalmente, agravian el interés público o lesionan derechos fundamentales.

Precisamente, el numeral 1 del artículo 20 del TUO de la Ley 27584 considera como una excepción al agotamiento de la vía administrativa el supuesto en el que la demanda es interpuesta por una entidad administrativa, conforme al supuesto contemplado en el segundo párrafo del artículo 13 antes referido.

19 El segundo párrafo del artículo 13 del TUO de la Ley 27584, Ley que Regula el Proceso Contencioso Administrativo, aprobado por el Decreto Supremo 011-2019-JUS, dispone a la letra lo siguiente: “También tiene legitimidad para obrar activa la entidad pública facultada por ley para impugnar cualquier actuación administrativa que declare derechos subjetivos; previa expedición de la resolución motivada en la que se identifique el agravio que aquella produce a la legalidad administrativa y al interés público, y siempre que haya vencido el plazo para que la entidad que expidió el acto declare su nulidad de oficio en sede administrativa". 
Finalmente, se debe tener presente que no estaremos ante un proceso de lesividad en el supuesto en que una entidad distinta a la emisora del acto administrativo formule una pretensión de nulidad contra tal acto. En ese caso, nos encontraremos ante una mera demanda contencioso-administrativa, en la cual la entidad accionante deberá acreditar que cuenta con legitimidad para obrar activa porque ocupó la posición de administrado en un procedimiento administrativo, o porque una ley especial faculta a una entidad a cuestionar los actos administrativos de otra.

\section{REFERENCIAS}

Baca, V. (2007). La inexistencia, una noción instrumental necesaria en el derecho administrativo peruano. En Derecho administrativo contemporáneo. Ponencias del II Congreso de Derecho Administrativo (pp. 251-260). Palestra Editores.

Bocanegra, R. (2006). Lecciones sobre el acto administrativo. Civitas.

Cassagne, J. C. (2013). El acto administrativo. Teoría y régimen jurídico. Temis.

Decreto Supremo 011-2019-JUS del 2019. Decreto Supremo que aprueba el Texto Único Ordenado de la Ley N. ${ }^{\circ} 27584$ - Ley que Regula el Proceso Contencioso Administrativo. 3 de mayo del 2019. https://busquedas.elperuano.pe/normas legales/decreto-supremo-que-aprueba-el-texto-unico-ordenado-de-la-ledecreto-supremo-n-011-2019-jus-1766381-1/?fbclid=IwAR1i737ooWOVxAhGxH sjuP7a5FtAky99Wd88hCeHF7bxmT8c3jdvBPmL9-A

Huapaya, R. (2006). Tratado del proceso contencioso-administrativo. Jurista Editores.

Jordano, J. (1997). Nulidad de los actos administrativos y derechos fundamentales. Marcial Pons.

Mora, J. (2011). La autotutela en el derecho administrativo. Un enfoque crítico. Temis.

Morón, J. C. (2015). El proceso contencioso de lesividad: catorce años después de su incorporación en el derecho peruano. lus et Veritas, 24(51), 224-246.

Morón, J. C. (2020). Comentarios a la Ley del Procedimiento Administrativo General (vols. I y II). Gaceta Jurídica.

Sánchez Morón, M. (2013). Derecho administrativo. Parte general. Tecnos.

Santamaría Pastor, J. A. (2004). Principios de derecho administrativo (vols. I y II). lustel. 
